\title{
The Determination of the Relationship Between Isokinetic Leg Strengths and Agility and Speed Performance of Elite Handball Players
}

\author{
Zait Burak Aktuğ ${ }^{1}$, Aykut Dündar ${ }^{2}$, Fatih Murathan ${ }^{2}$, Rüçhan Iri $^{1}$ \\ ${ }^{1}$ University of Niğde Ömer Halisdemir, School of Physical Education and Sports, Niğde, Turkey \\ ${ }^{2}$ University of Adıyaman, School of Physical Education and Sports, Adiyaman, Turkey \\ Correspondence: Zait Burak Aktuğ, University of Niğde Ömer Halisdemir, School of Physical Education and Sports, \\ Niğde, Turkey.
}

Received: April 2, 2018

doi:10.11114/jets.v6i6.3145
Accepted: April 14, $2018 \quad$ Online Published: April 17, 2018

URL: https://doi.org/10.11114/jets.v6i6.3145

\begin{abstract}
The aim of the study is to examine the relationship between isokinetic hamstring and quadriceps muscle strengths and agility and speed performance of elite male handball players. 15 male handball players participated in the study. The isokinetic leg forces of the handball players participating in the study were determined by isokinetic dynamometer, the agility performances by Ilionis and 505 agility test, and the speed performances by photocell. As a result of the analysis, there was no statistically significant relationship between isokinetic dominant and non-dominant leg hamstring and quadriceps peak torque forces and agility and speed performance at $60^{\circ} \mathrm{s}^{-1}$ and $400^{\circ} \mathrm{s}^{-1}$ angular speeds $(\mathrm{p}<0.05)$. As a result, it can be stated that there is no relation between hamstring and quadriceps muscle strength and speed and agility performances of handball players. This may be related to the requirements and physical characteristics of the handball branch (tall height, high weight, high BMI).
\end{abstract}

Keywords: isokinetic force, handball players, hamstring, quadriceps, agility, speed

\section{Introduction}

In addition to aerobic and anaerobic durability, strength, flexibility, balance, coordination, muscle and cardiorespiratory stability, high speed and agility skills are required for high performance in handball (Serdar, \& Bereket, 2001).

Agility is often defined as the ability to start and stop and change direction quickly (Little, \& Williams, 2005). Another definition is the ability of body position to be accurately controlled and preserved while changing a series of movements quickly (Sporis, Jukic, Milanovic, \& Vucetic, 2010). Movement time analysis results indicated that agility is a determinant of performance especially in indoor sports (handball, volleyball, etc.) (Sheppard, \& Young, 2006). Due to the different situations used in agility (for example, back-and-forth motion, etc.), agility performance can be improved through motor skills. For this reason, behind the development of agility, factors such as speed, power, and strength are mentioned (Little, \& Williams, 2005; Markovic, Sekulic, \& Markovic, 2007).

High speed performance such as agility is also required for high performance in handball. In handball, players perform a number of frequently repetitive short sprints (Sheppard, \& Young, 2006). In a handball game, an athlete was reported to have performed 60 to 70 speed-runs between 10 and 20 m (Chung, 1994). Especially in fastballs, speed performance plays an extremely important role. Speed, which means the ability of the athlete to move himself / herself from one place to another with the highest speed, is one of the most important motor skills determining the efficiency (Sevim, 2002). The relationship between strength and speed plays a crucial role in the high efficiency of sports (Bompa, 2015). The desired speed cannot be reached with an undeveloped strength (Schmidt, 1991). Studies have shown that there is a positive relationship between speed (Smirniotou et al., 2008; Harrison, Keane, \& Coglan, 2004; Harris, Cronin, Hopkins, \& Hansen, 2008) and agility (Markovic et al., 2007; Young, James, \& Montgomery, 2002; Nimphius, McGuigan, \& Newton, 2010) performances and hamstring and quadriceps muscle strengths.

The aim of this study is to examine the relationship between isokinetic hamstring and quadriceps muscle strengths and agility and speed performance of elite male handball players.

\section{Materials and Methods}

Men's Handball Super League teams of Adiyaman Municipality Sports Club participated in the study 2017-2018 season 
in Turkey. 15 elite male athletes still actively play in the league. The average height of handball players participating in the study is $188.79 \pm 6.90 \mathrm{~cm}$, body weight is $92.5 \pm 11.52 \mathrm{~kg}$, average age is $25.14 \pm 4.42$ year. Isokinetic leg strengths were measured on the first day and agility and speed performance were measured on the second day. Careful attention was paid to the fact that the athletes participating in the study did not have any injuries in the last six months and did not participate in any physical activity 24 hours before the measurements.

\subsection{Isokinetic Leg Strength Measurement}

The isokinetic muscle strengths of the lower extremities (knee) of the handball players participating in the study were measured through a Biodex brand isokinetic dynamometer (Biodex 3 Pro Medical System NY, Shirley) located in Adıyaman University Training and Research Hospital. A total of $10 \mathrm{~min}$ of warming was applied to the handball players before the test and they performed streching movements towards the lower extremity. All handball players' bodies and knee zones are fixed with bands and standardized. The players performed concentric isokinetic knee strength test consisting of 15 repetitions at an angular velocity of $60^{\circ} \mathrm{s}^{-1}$ and angular velocity and $400^{\circ} \mathrm{s}^{-1}$ angular velocity on both legs. For each angular speed before the start of the test, the athletes were given 3 trials. During the measurements, the athletes were given 3-minutes resting time between both legs and 60 seconds between each angular velocity.

\subsection{Ilionis Agility Test}

The Ilionis agility test was determined through a New Test 2000 photocell. The Ilionis agility test was applied on a test track consisting of three rows arranged on a straight line with a width of $5 \mathrm{~m}$, a length of $10 \mathrm{~m}$ and a width of $3.3 \mathrm{~m}$ in the middle part. The test consists of a slalom run between $40 \mathrm{~m}$ straight, $20 \mathrm{~m}$ long columns with $180^{\circ}$ turns every $10 \mathrm{~m}$. After the test track was prepared, a two-port photocell electronic chronometer system was installed, measuring $0.01 \mathrm{~s}$ at the start and end with precision. Before the test, the handball players were allowed to try for 2 minutes after the warm-up for 10 minutes. The subjects were out of the way at the starting line of the test track in a supine position and the hands were on the ground at shoulder level and tried to finish the course as soon as possible. The track closing time is recorded in milliseconds. With complete rest, the test was repeated 2 times and the best result was used in the study (Hazır, Mahir, \& Açıkada, 2010; Miller, Herniman, Ricard, Cheatham, \& Michael, 2006).

\subsection{Agility Test}

505 agility test was determined through a New Test 2000 photocell device. The test consists of a 10-meter approach course followed by a 5-meter round trip. After the course was established, both the start and stop gates of the photocell chronometer were placed on the $5 \mathrm{~m}$ line. The first door stop was located in the approach direction; the second one was located as the start. The round trip time of $5 \mathrm{~m}$ was recorded in seconds. Before the test, the handball players were allowed to try for 2 minutes after the warm-up for 10 minutes. The track closing time was recorded in milliseconds. With complete rest, the test was repeated 2 times and the best result was used in the study (Hazır et al., 2010; Gelder, \& Bartz, 2011).

\subsection{0 and $20 \mathrm{~m}$ Speed Performance}

$10 \mathrm{~m}$ and $20 \mathrm{~m}$ speed performances were determined through a New Test 2000 photocell device. Before the test, the athletes warmed up for 10 minutes. The track closing time was recorded in milliseconds. The test was repeated 2 times with full rest, the best result was used in the study.

\subsection{Statistical Analysis}

After the data were analyzed through the SPSS 24 software program, Spearman Correlation Analysis was used to determine the relationship between the isokinetic hamstring and quadriceps muscle strengths and the 505 agility test, the Ilionis agility test and the $10-20 \mathrm{~m}$ sprint performance.

\section{Findings}

Table 1. The handball players' average strength performances and $\mathrm{Sd}$

\begin{tabular}{llllll}
\hline $\mathbf{N m})$ & $\mathbf{N}$ & Minimum & Maximum & Mean & Sd \\
\hline $\mathrm{D} 60^{\circ} \mathrm{s}^{-1} \mathrm{PT}_{\mathrm{Q}}$ & 15 & 142.10 & 306.20 & 234.26 & 47.71 \\
$\mathrm{D} 60^{\circ} \mathrm{s}^{-1} \mathrm{PT}_{\mathrm{H}}$ & 15 & 87.40 & 206.70 & 158.05 & 34.55 \\
$\mathrm{D} 60^{\circ} \mathrm{s}^{-1} \mathrm{H} / \mathrm{Q}$ & 15 & 30.30 & 88.80 & 66.59 & 14.06 \\
\hline $\mathrm{ND} 60^{\circ} \mathrm{s}^{-1} \mathrm{PT}$ & 15 & 158.20 & 301.80 & 240.25 & 41.18 \\
$\mathrm{ND} 60^{\circ} \mathrm{s}^{-1} \mathrm{PT}_{\mathrm{H}}$ & 15 & 87.50 & 213.60 & 144.37 & 32.77 \\
$\mathrm{ND} 60^{\circ} \mathrm{s}^{-1} \mathrm{H} / \mathrm{Q}$ & 15 & 40.50 & 88.50 & 61.32 & 15.69 \\
\hline $\mathrm{D} 400^{\circ} \mathrm{s}^{-1} \mathrm{PT}_{\mathrm{Q}}$ & 15 & 115.40 & 196.50 & 157.50 & 23.90 \\
$\mathrm{D} 400^{\circ} \mathrm{s}^{-1} \mathrm{PT}_{\mathrm{H}}$ & 15 & 134.10 & 216.20 & 166.16 & 23.52 \\
$\mathrm{D} 400^{\circ} \mathrm{s}^{-1} \mathrm{H} / \mathrm{Q}$ & 15 & 85.10 & 131.60 & 112.78 & 11.71 \\
\hline $\mathrm{ND} 400^{\circ} \mathrm{s}^{-1} \mathrm{PT}_{\mathrm{Q}}$ & 15 & 100.10 & 186.20 & 144.77 & 25.42 \\
$\mathrm{ND} 400^{\circ} \mathrm{s}^{-1} \mathrm{PT}$ & 15 & 236.60 & 213.50 & 165.76 & 21.42 \\
$\mathrm{ND} 400^{\circ} \mathrm{s}^{-1} \mathrm{H} / \mathrm{Q}$ & 15 & 80.70 & 148.70 & 117.15 & 20.63 \\
\hline
\end{tabular}


$\mathrm{PT}=$ peak torque; $\mathrm{Q}=$ quadriceps; $\mathrm{H}=$ hamstrings; $\mathrm{Nm}=$ newton meter; $\mathrm{D}=$ dominant; $\mathrm{ND}=$ non-dominant

Table 2. The handball players' average agility and speed performance and $\mathrm{Sd}$

\begin{tabular}{llllll}
\hline (ms) & N & Minimum & Maximum & Mean & Sd \\
\hline Ilionis Test & 15 & 22729 & 27688 & 23826.85 & 1387.44 \\
\hline 505Test (Right) & 15 & 2489 & 3108 & 2692.85 & 168.32 \\
\hline 505 Testi (Left) & 15 & 2556 & 3055 & 2766.71 & 171.29 \\
\hline 10 m speed & 15 & 1529 & 1753 & 1643.71 & 77 \\
\hline 20 m speed & 15 & 2774 & 3346 & 2974.57 & 152.45 \\
\hline
\end{tabular}

Table 3. The relationship between handball players' isokinetic hamstring and quadriceps muscle strength and agility and speed performance

\begin{tabular}{|c|c|c|c|c|c|c|}
\hline & & 505 Test (Right) & 505 Test (Left) & Ilionis Test & $10 \mathrm{~m}$ Speed & $20 \mathrm{~m}$ Speed \\
\hline \multirow{3}{*}{$\mathrm{D} 60^{\circ} \mathrm{s}^{-1} \mathrm{PT}_{\mathrm{Q}}$} & $\mathrm{R}$ & .165 & .000 & -.007 & -.090 & .024 \\
\hline & $\mathrm{p}$ & .573 & 1.000 & .982 & .759 & .935 \\
\hline & $\mathrm{N}$ & 15 & 15 & 15 & 15 & 15 \\
\hline \multirow[t]{3}{*}{$\mathrm{D} 60^{\circ} \mathrm{s}^{-1} \mathrm{PT}_{\mathrm{H}}$} & $\mathrm{R}$ & -.024 & -.095 & -.319 & .235 & -.037 \\
\hline & $\mathrm{p}$ & .935 & .748 & .267 & .418 & .899 \\
\hline & $\mathrm{N}$ & 15 & 15 & 15 & 15 & 15 \\
\hline \multirow{3}{*}{$\mathrm{ND} 60^{\circ} \mathrm{s}^{-1} \mathrm{PT}_{\mathrm{Q}}$} & $\mathrm{R}$ & .319 & -.013 & .174 & .270 & .253 \\
\hline & $\mathrm{p}$ & .267 & .964 & .553 & .350 & .384 \\
\hline & $\mathrm{N}$ & 15 & 15 & 15 & 15 & 15 \\
\hline \multirow{3}{*}{$\mathrm{ND} 60^{\circ} \mathrm{s}^{-1} \mathrm{PT}_{\mathrm{H}}$} & $\mathrm{R}$ & .108 & -.220 & -.297 & -.037 & -.191 \\
\hline & $\mathrm{p}$ & .714 & .450 & .303 & .899 & .513 \\
\hline & $\mathrm{N}$ & 15 & 15 & 15 & 15 & 15 \\
\hline \multirow[t]{3}{*}{$\mathrm{D} 400^{\circ} \mathrm{s}^{-1} \mathrm{PT}_{\mathrm{Q}}$} & $\mathrm{R}$ & .415 & .178 & .332 & .301 & .376 \\
\hline & $\mathrm{p}$ & .140 & .542 & .246 & .296 & .185 \\
\hline & $\mathrm{N}$ & 15 & 15 & 15 & 15 & 15 \\
\hline \multirow[t]{3}{*}{$\mathrm{D} 400^{\circ} \mathrm{s}^{-1} \mathrm{PT}_{\mathrm{H}}$} & $\mathrm{R}$ & .480 & .119 & .163 & .224 & .323 \\
\hline & $\mathrm{p}$ & .083 & .685 & .578 & .441 & .259 \\
\hline & $\mathrm{N}$ & 15 & 15 & 15 & 15 & 15 \\
\hline \multirow[t]{3}{*}{$\mathrm{ND} 400^{\circ} \mathrm{s}^{-1} \mathrm{PT}_{\mathrm{Q}}$} & $\mathrm{R}$ & .165 & -.029 & .174 & .156 & .160 \\
\hline & $\mathrm{p}$ & .573 & .923 & .553 & .594 & .584 \\
\hline & $\mathrm{N}$ & 15 & 15 & 15 & 15 & 15 \\
\hline \multirow[t]{3}{*}{$\mathrm{ND} 400^{\circ} \mathrm{s}^{-1} \mathrm{PT}_{\mathrm{H}}$} & $\mathrm{R}$ & .270 & -.020 & .024 & .213 & .134 \\
\hline & $\mathrm{p}$ & .350 & .946 & .935 & .464 & 648 \\
\hline & $\mathrm{N}$ & 15 & 15 & 15 & 15 & 15 \\
\hline
\end{tabular}

$\mathrm{p}<0.05, \mathrm{R}=$ correlation coefficient, $\mathrm{p}=$ significance

Table 3 shows that there was no statistically significant correlation between isokinetic dominant and non-dominant leg hamstring and quadriceps peak torque strengths and agility and speed performance at $60^{\circ} \mathrm{s}^{-1}$ and $400^{\circ} \mathrm{s}^{-1}$ angular speeds $(\mathrm{p}<0.05)$.

\section{Discussion}

Agility performance, which is indicative of complex motor quality, or ability to change direction, or that is responsible for sudden stops and starts, is an important factor for the high performance of sports (Trnınıć, Marković, \& Heimer, 2001; Muller, Benko, Raschner, \& Schwameder, 2000). Agility performance consists of rapid deceleration and re-acceleration in the shortest time.

Quadriceps in the decelerating phase contributes to the agility performance while quadriceps contracts in the concentric manner in the acceleration phase (Simonsen et al., 2000). Furthermore, activation of the quadriceps muscle may be higher than $160 \%$ of the maximal contraction (Colby et al., 2000), while the force exerted on the outer bicep on the eccentric phase of maneuvers is more than three times of the body weight (Simonsen et al., 2000).

When these situations are taken into account, the hypothesis of the study is that there is a relationship between quadriceps muscle strength and agility. However, when the current literature is examined, it seems that there are various conflicting results. Davis, Barnette, Kiger, Mirasola, \& Young (2004) determined that there was a relationship between strength and agility in a study conducted with soccer players. In another study on soccer players, Young et al (2002) found a moderate $(r=0.54)$ relationship between strength in only one of 7 different directional velocity tests.

In a study related to the relationship between volleyball players' knee strengths and agility performances, there was no significant relationship between the players' knee strengths and agility performance (Yapıc1, 2016). Behm, Wahl, Button, Power, \& Anderson (2005) Gilenstram, Thorsen, Henriksson, \& Karin (2011) Potteiger, Smith, Maier, \& Foster (2010) stated that ice hockey players had no relationship between leg muscle strength and agility performance. Demirhan, 
Botobaev, Canuzakov, \& Geri (2017) compared the agility performance of athletes in different fields and found that soccer players and wrestlers had the best performance and basketball players had the worst agility performance value.

In a study involving 62 athletes from different branches (kick boxing, karate, taekwondo, wrestling and soccer) it was found that there was a positive correlation between agility performance and leg strength (Can, Özmen, \& Bayrakdaroğlu, 2017). In a study conducted on the elite skiers by Schultz et al (2015), it was found that there was a statistically significant relationship between the bar speed during the weighted squat bounce exercise and the agility values of the athletes.

As a result of the study, there was no significant relationship between the handball players' isokinetic hamstring and quadriceps muscle strength and agility performances. When the above studies are examined, it can be stated that the relationship between leg strength and agility shows differences from one branch to another. This may be due to the physical characteristics of the crucial factors influencing agility, the severity and content of the workouts.

In current study, there was no significant relationship between hamstring and quadriceps muscle strength and speed performance. On the contrary, in a study conducted by Aktuğ, Harbilli, \& Harbilli (2016) it was stated that hamstring and quadriceps muscle strengths were a crucial factor in the speed performance of soccer players aged 17-20 years. Similarly, Deprez et al (2015) and Gökhan, Aktaş, \& Aysan (2015) reported that the increase in leg strength of soccer players was an important effect on the speed performance.

Behm et al (2005) Gilenstram et al (2011) Potteiger et al (2010) stated that ice hockey players had no relationship between leg muscle strength and speed performance. Similar to Kin-İşler, Ariburun, Özkan, Aytar, \& Tandogan (2008) Newman, Tarpenning, \& Marino (2004) found a positive relationship between speed and leg strength of rugby players, while not finding a relationship between the speed and leg strength of the players.

Zorba, Kemal, \& Şenol (2005) found no correlation between the speed performances and leg strengths of handball players. Zorba et al (2005) found that there was no correlation between hamstring and quadriceps muscle strengths and speed performance of handball players participating in their study, which supports the current study.

When the above studies are examined, it can be suggested that the relationship between leg strength and speed is different varies from one branch to another. This may be due to the fact that the need for speed performance differs grossly according to branches and it is related to the severity and content of the workouts.

As a result, it can be stated that there is no relation between handball players' hamstring and quadriceps muscle strength and speed and agility performances.

\section{References}

Aktuğ, Z. B., Harbilli, E., \& Harbilli, S. (2015). Comparison of isokinetic knee strength between the dominant and non-dominant legs and relationships among isokinetic strength vertical jump, and speed performance in soccer players. Turkiye Klinikleri Journal of Sports Sciences, 8(1), 8-14. https://doi.org/10.5336/sportsci.2015-47409

Behm, D. G., Wahl, M. J., Button, D. C., Power, K. E., \& Anderson, K. G. (2005). Relationship between hockey skating speed and selected performance measures. Journal of Strength Condition Research, 19(2), 326-331. https://doi.org/10.1519/R-14043.1

Bompa, T. O. (2015). Antrenman Kuramı ve Yöntemi, Ankara, Spor Yayınevi ve Kitapevi.

Can, İ., Özmen, M., \& Bayrakdaroğlu, M. (2017). The relationship between velocity and power values during loaded-squat jump exercise and agility in trained athletes. University of Celal Bayar Physical Education and Sport Sciences, 12(2), 136-144.

Chung, H. K. (1994). Hentbol Temel Oyunu, I. Uluslararası Hentbol Sempozyumu, İstanbul.

Colby, S., Francisco, A., Yu, B., Kirkendall, D., Finch, M., \& Garrett, W. (2000). Electromyographic and kinematic analysis of cutting maneuvers. American Journal of Sport Medicine, 28(2), 234-240. https://doi.org/10.1177/03635465000280021501

Davis, D. S., Barnette, B. J., Kiger, J. T., Mirasola, J. J., \& Young, S. M. (2004). Physical characteristics that predict functional performance in Division I college football players. Journal of Strength Condition Research, 18(1), 115-120.

Demirhan, B., Botobaev, B., Canuzakov, K., \& Geri, S. (2017). Investigation of agility levels according to different sport branches. Turkish Journal of Sport and Exercise, 19(1), 1-6.

Deprez, D., Fransen, J., Boone, J., Lenoir, M., Philippaerts, R., \& Vaeyens, R. (2015). Characteristics of high level youth soccer players: variation by playing position. Journal of Sports Sciences, 33(3), 243-54. https://doi.org/10.1080/02640414.2014.934707 
Gelder, V. L., \& Bartz, S. D. (2011). The effect of acute stretching on agility performance. Journal of Strength Condition Research, 25(11), 3014-3021. https://doi.org/10.1519/JSC.0b013e318212e42b

Gilenstam, K. M., Thorsen, K., Henriksson, L., \& Karin, B. (2011). Physiological correlates of skating performance in women's and men's ice hockey. Journal of Strength Condition Research, 25(8), 2133-2142. https://doi.org/10.1519/JSC.0b013e3181ecd072

Gökhan, I., Aktaş, Y., \& Aysan, H. A. (2015). Evaluation of the relationship between leg strength and velocity values in amateur football players. International Journal of Science Culture and Sport, 3(4), 47-54. https://doi.org/10.14486/IJSCS356

Harris, N. K., Cronin, J. B., Hopkins, W. G., \& Hansen, K. T. (2008). Relationship between sprint times and the strength/power outputs of a machine squat jump. Journal of Strength Condition Research, 22(3), 691-698. https://doi.org/10.1519/JSC.0b013e31816d8d80

Harrison, A. J., Keane, S. P., \& Coglan, J. (2004). Force-velocity relationship and stretch-shortening cycle function in sprint and endurance athletes. Journal of Strength Condition Research, 18(3), 473-479. https://doi.org/10.1519/13163.1

Hazır, T., Mahir, Ö. F., \& Açıkada, C. (2010). Relationship between agility and body composition, anaerobic power in young soccer players. Hacettepe Journal of Sport Sciences, 21(4), 146-153. https://doi.org/10.2478/v10078-012-0088-3

Kin-İşer, A., Ariburun, B., Özkan, A., Aytar, A., \& Tandogan, R. (2008). The relationship between anaerobic performance, muscle strength and sprint ability in American football players. Isokinetic and Exercise Sciences, 16(2), 87-92.

Little, T., \& Williams, A. G. (2005). Specificity of acceleration, maximum speed and agility in professional soccer players. Journal of Strength Condition Research, 19, 76-78. https://doi.org/10.1519/14253.1

Markovic, G., Sekulic, D., \& Markovic, M. (2007). Is agility related to strength qualities? Analysis in latent space. Collegium Antropologicum, 31, 787-793.

Miller, M. G., Herniman, J. J., Ricard, M. D., Cheatham, C. C., \& Michael., T. J. (2006). The effects of a 6 week plyometric training program on agility. Journal of Sport Sciences and Medicine, 5(3), 459-460.

Muller, E., Benko, U., Raschner, C., \& Schwameder. H. (2000). Specific fitness training and testing in competitive sports. Medicine Science in Sport Exercise, 32(1), 216-220. https://doi.org/10.1097/00005768-200001000-00032

Newman, M. A., Tarpenning, K. M., \& Marino, F. E. (2004). Relationships between isokinetic knee strength, single-sprint performance, and repeated-sprint ability in football players. Journal of Strength Condition Research, 18(4), 867-72. https://doi.org/10.1519/13843.1

Nimphius, S., McGuigan, M. R., \& Newton, R. U. (2010). Relationship between strength, power, speed and change of direction performance of female softball players. Journal of Strength Condition Research, 24(4), 885-895. https://doi.org/10.1519/JSC.0b013e3181d4d41d

Potteiger, J. A., Smith, D. L., Maier, M. L., \& Foster, T. S. (2010). Relationship between body composition, leg strength, anaerobic power, and on-ice skating performance in division I mens hockey athletes. Journal of Strength Condition Research, 24(7), 1755-1762. https://doi.org/10.1519/JSC.0b013e3181e06cfb

Schmidt, R. A. (1991). Motor Learling and Performance, USA, Human Kinetics Pubmed, 18.

Schultz, F. A., Cavazzoni, P., Carnevale, R. V., Abad, C. C., Kobal, R., Pereira, L. A., \& Loturco, I. (2015). Speed and power predictors of change of direction ability in elite snow athletes. Journal of Human Sport and Exercise, 10(4), 847-856. https://doi.org/10.14198/jhse.2015.104.02

Serdar, E., \& Bereket, S. (2001). Comparison of motoric and physiological parameters of elite Turk and foreing handball players. Gazi Journal of Physical Education and Sport Sciences, 4(4), 44-52.

Sevim, Y. (2002). Antrenman Bilgisi, Ankara, Nobel Yay Dağ, 29-109.

Sheppard, J. M., \& Young, W. B. (2006). Agility literature review: Classifications, training and testing. Journal of Sports Sciences, 24(9), 919-932. https://doi.org/10.1080/02640410500457109

Simonsen, E. B., Magnusson, S. P., Bencke, J., Naesborg, H., Havkrog, M., Ebstrup, J. F., \& Sørensen, H. (2000). Can the hamstring muscles protect the anterior cruciate ligament during a side-cutting maneuver?. Scandinavian Journal of Medicine and Sciences Sport, 10(2), 78-84. https://doi.org/10.1034/j.1600-0838.2000.010002078.x

Smirniotou, A., Katsikas, C., Paradisis, G., Argeitaki, P., Zacharogiannis, E., \& Tziortzis, S. (2008). Strength-power 
parameters as predictors of sprinting performance, The Journal of Sport Medicine and Physical Fitness, 48(4), 447-454.

Sporis, G., Jukic, I., Milanovic, L., \& Vucetic, V. (2010). Reliability and factorial validity of agility tests for soccer players. Journal of Strength Condition Research, 24(3), 679-686. https://doi.org/10.1519/JSC.0b013e3181c4d324

Trnınıć, S., Markovıć, G., \& Heımer, S. (2011). Effects of developmental training of basketball cadets realised in the competitive period. Collegium Antropologicum, 25(2), 591-604.

Yapic1, A. (2016). Evaluation of the relationship between isokinetic strength and field performance in professional male volleyball players. European Journal of Physical Education Sport Sciences, 2(6), 39-49. https://doi.org/10.5281/zenodo.215206

Young, W. B., James, R., \& Montgomery, I. (2002). Is muscle power related to running speed with changes of direction?, The Journal of Sport Medicine and Physical Fitness, 42(3), 282-288.

Zorba, E., Kemal, G., \& Şenol, G. (2015). Examining relationships between some physical fitness parameters of elite handball players. International Journal of Sciences Culture and Sport, 2(Special Issue 1), 68-76. https://doi.org/10.14486/IJSCS75

\section{Copyrights}

Copyright for this article is retained by the author(s), with first publication rights granted to the journal.

This is an open-access article distributed under the terms and conditions of the Creative Commons Attribution license which permits unrestricted use, distribution, and reproduction in any medium, provided the original work is properly cited. 